\title{
Leptin promotes the proliferation and migration of human breast cancer through the extracellular-signal regulated kinase pathway
}

\author{
HONG-JUN YUAN, KE-WANG SUN and KUN YU
}

Department of General Surgery, Zhejiang Provincial People's Hospital, Hangzhou, Zhejiang 310014, P.R. China

Received June 22, 2013; Accepted October 23, 2013

DOI: $10.3892 / \mathrm{mmr} .2013 .1786$

\begin{abstract}
Obesity has been associated with an increased risk of postmenopausal breast cancer, which may be due to the expression of leptin. The aim of this study was to determine the role of leptin in the growth of breast cancer cells in nude mice, the proliferation and migration of MCF-7 human breast cancer cells and its downstream signaling pathway. The xenograft mouse model was elicited by injecting MCF-7 human breast cancer cells into the left back axilla and the tumor size was measured every other day. Leptin injected subcutaneously around the tumor site led to an increase in the size and weight of the tumor, whereas the leptin antagonist (LA) significantly inhibited the size and weight of the tumor. Leptin promoted the proliferation and migration of MCF-7 cells and LA inhibited it. The effects of leptin on increasing the size and weight of the tumor in the nude mice and the proliferation and migration of MCF-7 human breast cancer cells were eradicated by pretreatment with LA, the extracellular-signal regulated kinase (ERK) inhibitor PD98059. In the xenograft mouse model the leptin level was increased and leptin increased the phosphorylation of ERK in the MCF-7 cells, whereas LA significantly reduced the phosphorylation of ERK. These results indicated that leptin promotes the growth of breast cancer in the nude mice and increases the proliferation and migration of MCF-7 human breast cancer cells via the ERK pathway.
\end{abstract}

\section{Introduction}

Breast cancer is the most common type of cancer in females (1), which is associated with genetic background (2), reproductive factors (3), nutrition (4), body composition $(5,6)$ and obesity (7). It has been demonstrated that obesity increases the risk of breast cancer in postmenopausal females by $30-50 \%$, a high body mass index has been identified to correlate markedly with an increased risk of inflammatory breast cancer in

Correspondence to: Dr Kun Yu, Department of General Surgery, Zhejiang Provincial People's Hospital, 158 Shangtang Road, Hangzhou, Zhejiang 310014, P.R. China

E-mail: yukun_1006@163.com

Key words: breast cancer, leptin, proliferation, migration, extracellular-signal regulated kinase premenopausal and postmenopausal populations (8). However, the molecular mechanisms of obesity-induced breast carcinogenesis remain unclear.

One hypothesis is that the high levels of adipokines produced by adipose cells may be capable of promoting the development of breast cancer. Leptin is recognized as the most prominent adipokine to correlate with breast cancer. Leptin as a hormone is primarily synthesized and secreted by white adipose tissue and was first cloned in 1994 (9). Leptin is primarily involved in the regulation of food intake and energy expenditure (10-12) and is closely correlated with obesity (13). It has been reported that leptin levels are positively correlated with weight gain (14). Furthermore, studies have observed that leptin is capable of modulating several other processes, including angiogenesis (15), fertility (16) and immune response (17). In addition, evidence suggests that leptin may be involved in tumorigenesis, particularly in the development of breast, colorectal and prostate cancer (8). Breast cancer patients exhibited significantly higher leptin levels compared with the corresponding controls (18) and the expression of leptin and leptin receptors is more frequent in larger tumors (19). However, the precise correlation between leptin and breast cancer is not well understood.

Several studies have suggested that leptin activities are mediated through the transmembrane leptin receptor that, upon binding toleptin, is capable of stimulating the Janus kinase/signal transducer and activator of transcription (JAK/STAT), phosphoinositide 3-kinase (PI3K)/protein kinase B (AKT) and extracellular-signal regulated kinase (ERK) pathways $(20,21)$. It has been demonstrated that leptin is capable of inducing proliferation through the activation of the $N F-\kappa B$ and ERK1/2-dependent pathways in addition to upregulating c-fos expression in colonic epithelial cells (22-24). Furthermore, leptin may increase the growth and survival of prostate cancer cells through either the PI3K/AKT or ERK1/2 pathways (25). However, the mechanisms for leptin signaling in breast cancer are unclear. The aim of the present study was to determine the role of the leptin in the growth of breast cancer cells in nude mice, the proliferation and migration of MCF-7 human breast cancer cells and the downstream signaling pathway.

\section{Materials and methods}

Mice and xenograft model. Female nude mice (age, 4-6 weeks; average weight, 15-20 g) were purchased from the Chinese Academy of Medical Sciences Laboratory Animal Center. The 
mice were housed in a temperature- and humidity-controlled room with a 12-hour on-off light cycle and provided with access to food and water ad libitum. In order to establish the xenograft mouse model, MCF-7 human breast cancer cells were diluted with phosphate-buffered saline (PBS) at a concentration of $5 \times 10^{7}$ cells $/ \mathrm{ml}$ and $100 \mu \mathrm{l} \mathrm{MCF-7} \mathrm{human}$ breast cancer cells in PBS were injected subcutaneously into the left back axilla of each mouse (26). Normotensive sham-operated (Sham) mice underwent a similar surgical process, except without the injection of MCF-7 human breast cancer cells. The study was approved by the Ethics Committee of Zhejiang Provincial People's Hospital, Hangzhou, China Tumor size was calculated according to the following formula: Length x width x depth x 0.5236 (27).

Cells and cell culture. MCF-7 human breast cancer cells were purchased from the Chinese Academy of Medical Sciences Cancer Institute (Beijing, China) and cultured in phenol red-free Dulbecco's modified Eagle's medium (Invitrogen Life Technologies, Carlsbad, CA, USA) supplemented with $10 \%$ charcoal-stripped fetal bovine serum (FBS; Invitrogen Life Technologies). Cells were subcultured every 3-5 days to maintain logarithmic growth until a sufficient number of cells $\left(5 \times 10^{7}\right.$ cells $\left./ \mathrm{ml}\right)$ were obtained for transfer to nude mice.

Western blotting. Cells $\left(5 \times 10^{6}\right)$ were lysed in modified RIPA or lysed directly in $1 \mathrm{X}$ SDS loading buffer. Following electrophoresis and transmembrane, proteins on a nitrocellulose membrane were probed with the ERK, P-ERK (1:500: Cell Signaling Technology, Inc., Danvers, MA, USA), GAPDH (Bioworld Technology Inc., St. Louis Park, MN, USA) primary antibodies followed by incubation with goat anti-rabbit IgG secondary antibodies conjugated to horseradish peroxidase (1:5000; Immunology Consultants Lab, Portland, OR, USA). The bands were visualized by enhanced chemiluminescence (ECL) (Pierce Chemical Co., Rockford, IL, USA) and captured on X-ray films.

Blood sampling and leptin measurement. Blood samples were collected in a tube containing EDTA-K2. Immediately following centrifugation at 2,000 x g for $10 \mathrm{~min}$ (Eppendorf $\mathrm{AG}$, Hamburg, Germany), the plasma was frozen at $-70^{\circ} \mathrm{C}$ until it was assayed. Leptin concentrations were measured with a leptin enzyme-linked immunosorbent assay (ELISA) kit (Millipore, Billerica, MA, USA) according to the manufacturer's instructions.

Cell proliferation assay. Cell proliferation was assessed by bromodeoxyuridine (BrdUrd) incorporation using a BrdUrd ELISA colorimetric assay (Roche Diagnostics, Mannheim, Germany). To determine the proliferation of MCF-7 cells, the cells were initially plated at a density of $2 \times 10^{5}$ per $60 \mathrm{~mm}$ dish. Once the cells had been incubated, they were counted using a hemocytometer (Neubauer, Horsham Germany) and subsequently plotted.

Cell migration assay. Cell migration was assessed using Boyden chamber migration assays. Cells ( $10^{5}$ cells/well) were suspended in $0.5 \mathrm{ml}$ of $1 \%$ fetal bovine serum (FBS) minimal essential medium (MEM) and placed in the top chamber of
A

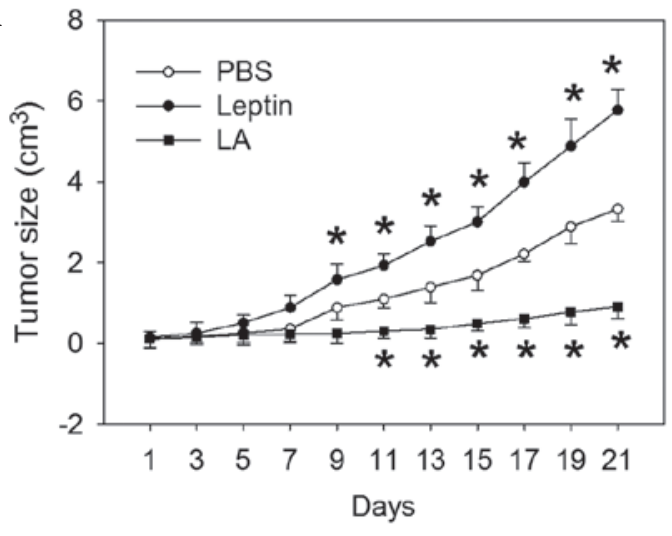

B

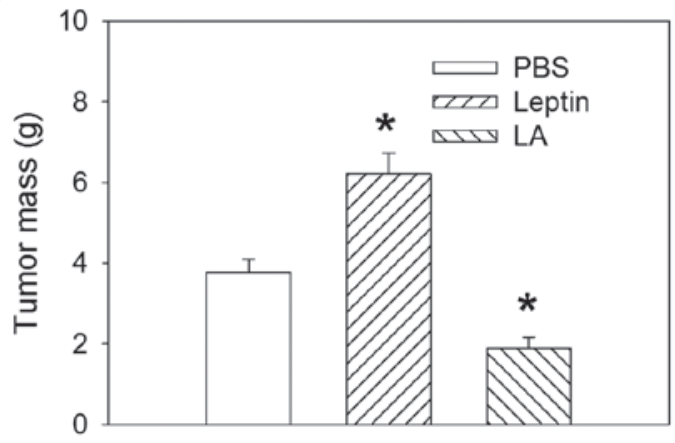

Figure 1. Effects of leptin and LA on tumor size and weight. (A) Effects of the subcutaneous injection of PBS, leptin or LA around the tumor site on tumor size. (B) Effects of the subcutaneous injection of PBS, leptin or LA around the tumor site on tumor weight. Tumor size was measured every other day and the tumor weight was measured 3 weeks following treatment. Values are provided as the mean \pm standard error. ${ }^{*} \mathrm{P}<0.05$ vs. PBS. LA, leptin antagonist; PBS, phosphate-buffered saline

the well; $0.750 \mathrm{ml}$ of $10 \%$ FBS MEM was added to the bottom compartment. Following a 48-h incubation, non-migrating cells were scraped from the membrane of the top compartment and cells that had migrated through the membrane were fixed and stained using the Protocol Diff-Quik 3 stain set (Siemens, Munich, Germany). Membranes were excised and mounted on a standard microscope slide (Curtin Matheson Scientific, Inc., Houston, TX, USA). The numbers of cells that migrated were determined from five random high-power fields (HPFs) visualized at x200 magnification.

Chemicals. Leptin was purchased from Sigma-Aldrich (St. Louis, MO, USA). Leptin antagonist (LA) triple mutant rat recombinant was obtained from ProSpec (Ness-Ziona, Israel). PD98059 and the ERK inhibitor, was purchased from Cayman Chemical (Ann Arbor, MI, USA). All chemicals were dissolved in PBS. The doses of leptin, LA and PD98059 in this study were $100 \mu \mathrm{g} / \mathrm{ml}, 1000 \mu \mathrm{g} / \mathrm{ml}$ and $20 \mathrm{nmol} / \mathrm{ml}$, respectively.

Statistical analysis. Data were analyzed using SPSS for Windows, version 18 (IBM, Armonk, NY, USA). Comparisons between two observations were assessed using Student's paired t-test. One-way or two-way analysis of variance was used followed by the Bonferroni test for post hoc analysis when multiple comparisons were made. All data are expressed as the means \pm standard error. $\mathrm{P}<0.05$ was considered to indicate a statistically significant difference. 
A

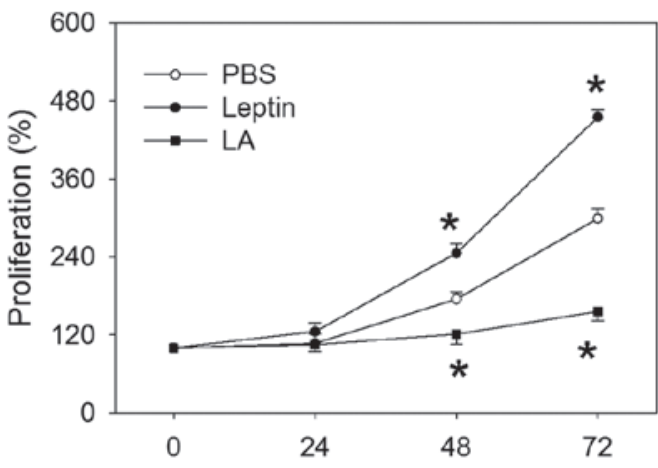

(h)

B

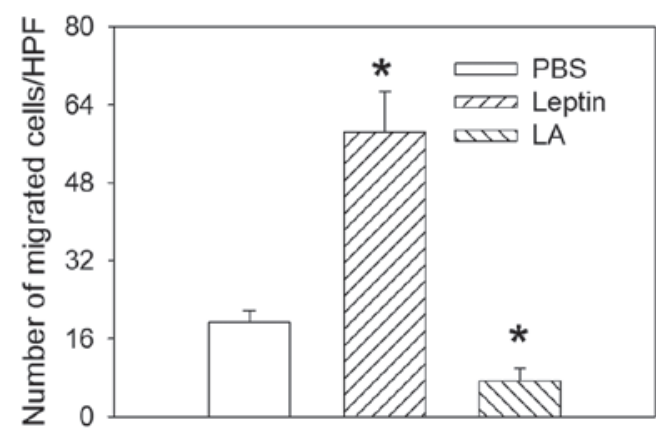

Figure 2. Effects of leptin and LA on proliferation and migration. (A) Effects of MCF-7 cells treated with PBS, leptin or LA on proliferation. (B) Effects of MCF-7 cells treated with PBS, leptin or LA on migration. Values are provided as the mean \pm standard error. " $\mathrm{P}<0.05$ vs. PBS. PBS, phosphate-buffered saline; LA, leptin antagonist; HPF, high-power fields.

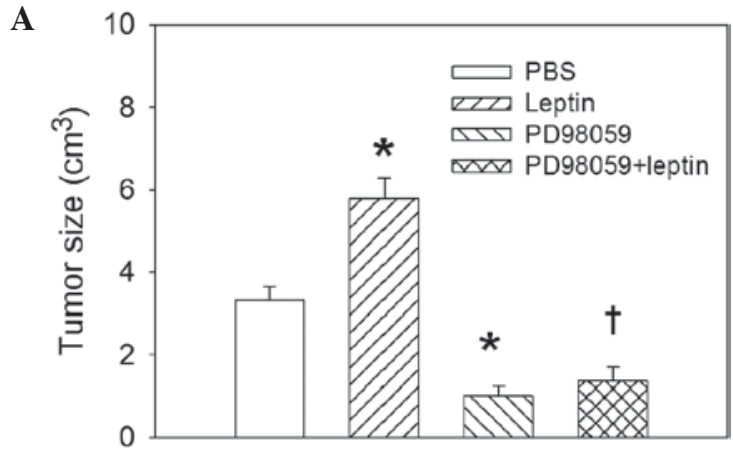

B

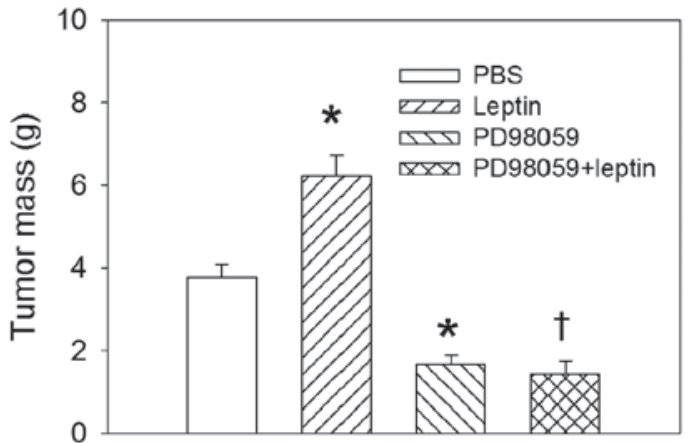

Figure 3. Effects of ERK inhibitor PD98059 on tumor size and weight. (A) Effects of the subcutaneous injection with PBS, leptin or ERK inhibitor PD98059 around the tumor site following pretreatment with PD98059 on tumor size. (B) Effects of the subcutaneous injection with PBS, leptin or ERK inhibitor PD98059 around the tumor site following pretreatment with PD98059 on tumor weight. Tumor size and weight was measured 3 weeks after treatment. Values are provided as the mean \pm standard error. ${ }^{*} \mathrm{P}<0.05$ vs. $\mathrm{PBS}$; and ${ }^{\dagger} \mathrm{P}<0.05$ vs. leptin. ERK, extracellular-signal regulated kinase; PBS, phosphate-buffered saline.
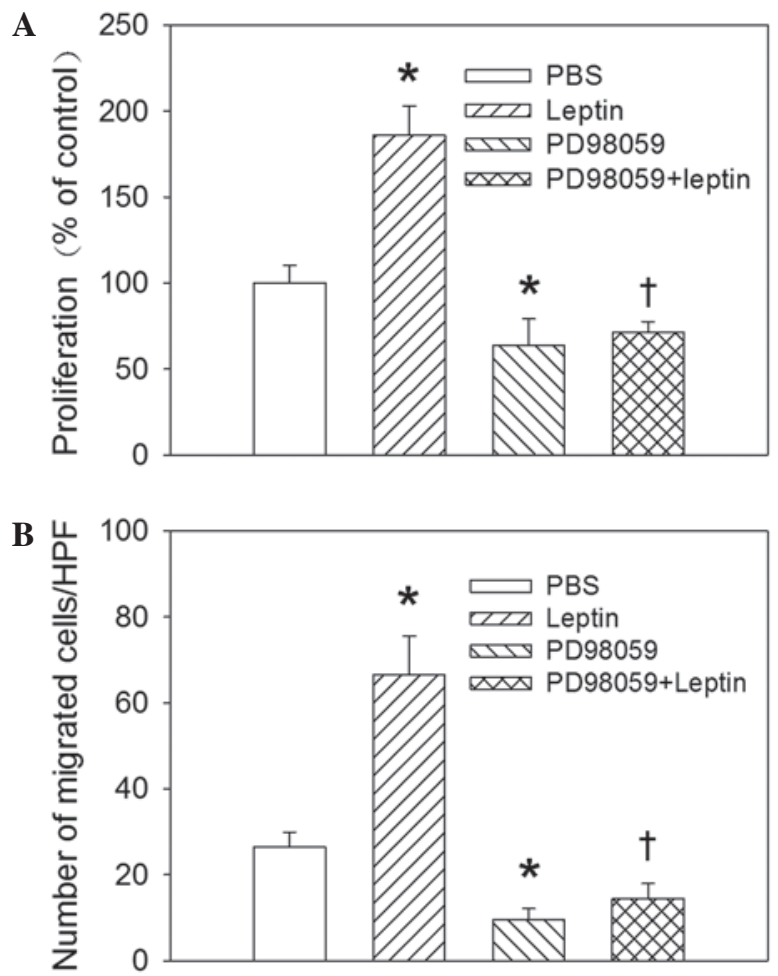

Figure 4. Effects of ERK inhibitor PD98059 on proliferation and migration. (A) Effects of MCF-7 cells treated with PBS, leptin or ERK inhibitor PD98059 following pretreatment with PD98059 on cell proliferation. (B) Effects of MCF-7 cells treated with phosphate-buffered saline, leptin or ERK inhibitor PD98059 following pretreatment with PD98059 on cell migration. Values are presented as the mean \pm standard error. ${ }^{*} \mathrm{P}<0.05$ vs. PBS; and ${ }^{\dagger} \mathrm{P}<0.05$ vs. leptin. ERK, extracellular-signal regulated kinase; PBS, phosphate-buffered saline.
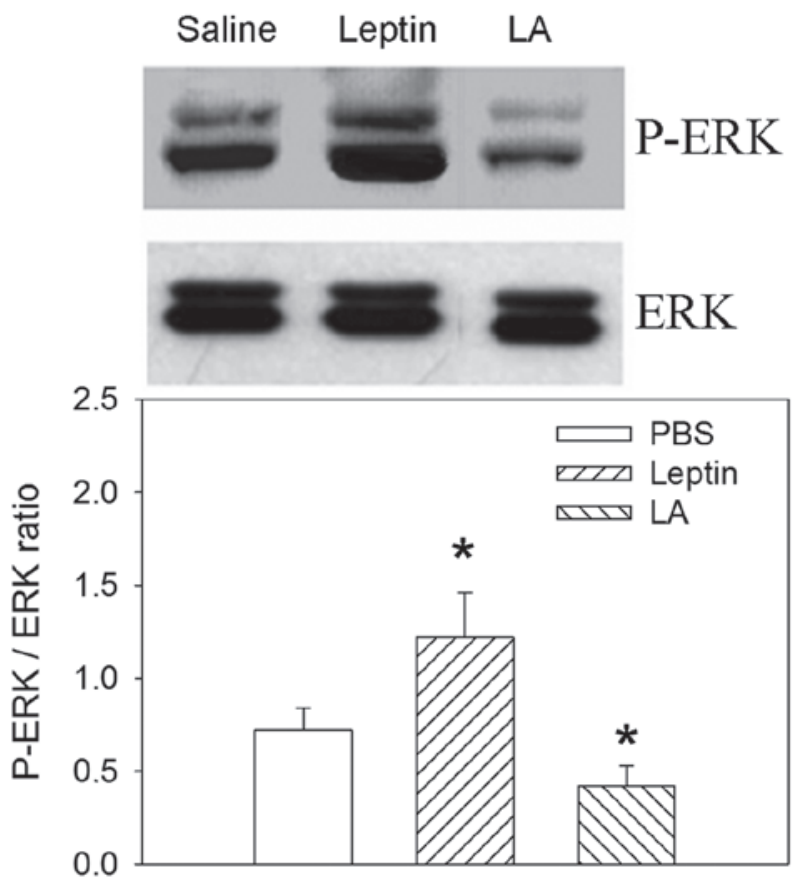

Figure 5. Effects of leptin and leptin antagonist on ERK phosphorylation. Leptin increased the phosphorylation of ERK in the MCF-7 cells $2 \mathrm{~h}$ after treatment, (LA) significantly reduced the phosphorylation of ERK in the MCF-7 cells compared with PBS. Values are presented as the means \pm SE. ${ }^{*} \mathrm{P}<0.05$ vs. PBS. ERK, extracellular-signal regulated kinase; LA, leptin antagonist; P-ERK, phosphorylated ERK; PBS, phosphate-buffered saline. 


\section{Results}

Effects of leptin and LA on tumor size and weight. Injection of leptin subcutaneously around the tumor site caused an increase in the tumor size from nine days following treatment and mean tumor weight after 3 weeks, whereas LA significantly inhibited the size of tumor from 11 days following treatment and the mean tumor weight after 3 weeks compared with PBS (Fig. 1). The level of leptin in the plasma was higher in xenograft mice compared with sham mice $(8.95 \pm 1.23 \mathrm{ng} / \mathrm{ml}$ vs. $4.73 \pm 0.82 \mathrm{ng} / \mathrm{ml}, \mathrm{P}=0.025)$.

Effects of leptin and LA on cell proliferation and migration. MCF-7 cells treated with leptin promoted MCF-7 cell proliferation compared with PBS at 48 and $72 \mathrm{~h}$, whereas LA inhibited their proliferation. In Boyden chamber migration assays, leptin induced the migration of MCF-7 cells, whereas LA inhibited their migration (Fig. 2).

Effects of the ERK inhibitor on tumor size and weight. The subcutaneous injection of ERK inhibitor PD98059 around the tumor site inhibited the tumor size and the mean tumor weight after 3 weeks compared with PBS, and eliminated the leptin-induced increase in tumor size and weight (Fig. 3).

Effects of ERK inhibitor on proliferation and migration. Treatment with ERK inhibitor PD98059 inhibited the proliferation of MCF-7 cells compared with PBS after $48 \mathrm{~h}$, and eliminated the increased proliferation induced by leptin. PD98059 also inhibited the migration of MCF-7 cells compared with the control cells and eradicated the increase in the migration caused by leptin (Fig. 4).

Effects of leptin and LA on ERK phosphorylation. Leptin increased the expression of phosphorylated ERK (P-ERK) in MCF-7 cells $2 \mathrm{~h}$ following treatment, LA significantly reduced the phosphorylation of ERK in MCF-7 cells compared with PBS (Fig. 5).

\section{Discussion}

Obesity is associated with an increased risk of breast cancer (28), particularly in postmenopausal females $(29,30)$. Leptin, a polypeptide hormone encoded by the obese gene, is synthesized and secreted primarily by white adipose tissue (9). As a growth factor in normal and malignant breast cells, leptin is capable of controlling the proliferation of normal and malignant breast epithelial cells (31). Leptin is a prominent adipokine, which may be associated with breast cancer. The present study demonstrates that leptin promotes the growth of breast cancer in nude mice and increases the proliferation and migration of MCF-7 cells via the ERK pathway.

Leptin and the leptin receptor have been characterized in MCF-7 breast cancer cell lines (32). Previous studies have demonstrated that immunodeficient mice hosting MCF-7 cells, which were treated with pegylated leptin peptide receptor antagonist 2 exhibited a significant reduction in the growth of tumor explants (33). In the present study, xenograft mice elicited increased leptin levels in the plasma compared with the sham group, by injecting MCF-7 cells into the left back axilla. Injecting leptin subcutaneously around the tumor site led to an increase in the size of the tumor and the mean tumor weight, whereas LA markedly inhibited the size of the tumor and the mean tumor weight compared with PBS. These results demonstrate that leptin promotes the growth of breast cancer in immunodeficient mice. The additional leptin expressed by the breast cancer cells in the xenograft mice may bind to the transmembrane leptin receptor directly or affect the cancer cells through the blood circulation indirectly to influence the growth of the breast cancer.

It has been demonstrated that co-cultures with human mammary adipocytes increase the viability of MCF-7 cells to a greater extent (34). Furthermore, the conditioned media from preadipocyte-derived adipocytes, but not that from undifferentiated preadipocytes, increased MCF-7 cell proliferation (35). Dietary fat increases mammary tumor growth and metastasis, thereby increasing the risk of mortality in obesity-resistant mice (36). Leptin has been implicated in breast cancer development as a determinant for the tumorpromoting activity of cancer-associated fibroblasts (CAFs) in breast cancer cells. Human CAFs stimulated an increase in the proliferation and migration of breast cancer cells (37). Fibroblast growth with tumor cells resulted in increased production of chemokines whose source was the CAFs themselves. Chemokines such as leptin produced under these 'mixed' conditions promoted tumor promalignancy activities (38-40). The bidirectional cross-talk between breast cancer cells and CAFs drives tumor progression via leptin signaling (37). In the present study, MCF-7 cells treated with leptin promoted cell proliferation and migration, whereas LA suppressed the proliferation and migration of MCF-7 cells. These results indicate that leptin is associated with obesity-related breast cancer development and progression.

Leptin acts via multiple intracellular signaling pathways, including STAT3, ERK and PI3K/AKT, to modulate cellular and organismal physiology (41). MAPK and PI3K inhibitors markedly blocked leptin-induced proliferation (42). In human breast epithelial HBL100 cells and human breast carcinoma-derived T-47D cells, leptin increases the expression of phosphorylated STAT3 and P-ERK (31). In this study, leptin increased the expression of P-ERK in MCF-7 cells whereas LA significantly reduced the phosphorylation of ERK in the MCF-7 cells. ERK inhibitor PD98059 inhibited the size of the tumor and the mean tumor weight and eliminated leptin-induced tumor size and mean weight increases in nude mice. Furthermore, PD98059 inhibited the proliferation of MCF-7 cells and eradicated the increased proliferation induced by leptin. PD98059 also inhibited the migration of MCF-7 cells and eliminated the increase in migration caused by leptin. These results indicate that the downstream ERK pathway is important in leptin signaling to regulate the growth, proliferation and migration of breast cancer, which is supported by previous findings that the ERK signal transduction pathway is involved the proliferative effect of MCF-7 cells (43).

In conclusion, leptin promotes the growth of breast cancer cells in nude mice and increases the proliferation and migration of MCF-7 human breast cancer cells. Furthermore, the ERK pathway is important in leptin signaling in order to regulate the growth, proliferation and migration of breast cancer. 


\section{References}

1. Jemal A, Siegel R, Xu J and Ward E: Cancer statistics, 2010. CA Cancer J Clin 60: 277-300, 2010.

2. Cao W, Wang X and Li JC: Hereditary breast cancer in the Han Chinese population. J Epidemiol 2: 75-84, 2013.

3. Kobayashi S, Sugiura H, Ando Y, Shiraki N, Yanagi T, Yamashita $\mathrm{H}$ and Toyama T: Reproductive history and breast cancer risk. Breast Cancer 19: 302-308, 2012

4. Hauner D, Janni W, Rack B and Hauner H: The effect of overweight and nutrition on prognosis in breast cancer. Dtsch Arztebl Int 108: 795-801, 2011

5. Irwin ML, Alvarez-Reeves M, Cadmus L, et al: Exercise improves body fat, lean mass, and bone mass in breast cancer survivors. Obesity (Silver Spring) 17: 1534-1541, 2009.

6. Schmitz KH, Ahmed RL, Hannan PJ and Yee D: Safety and efficacy of weight training in recent breast cancer survivors to alter body composition, insulin, and insulin-like growth factor axis proteins. Cancer Epidemiol Biomarkers Prev 14: 1672-1680, 2005.

7. Demark-Wahnefried W, Campbell KL and Hayes SC: Weight management and its role in breast cancer rehabilitation. Cancer 118: 2277-2287, 2012

8. Garofalo C and Surmacz E: Leptin and cancer. J Cell Physiol 207: $12-22,2006$

9. Zhang Y, Proenca R, Maffei M, Barone M, Leopold L and Friedman JM: Positional cloning of the mouse obese gene and its human homologue. Nature 372: 425-432, 1994

10. Kontos A, de Menezes RC, Ootsuka Y and Blessing W: Brown adipose tissue thermogenesis precedes food intake in genetically obese Zucker (fa/fa) rats. Physiol Behav 118: 129-137, 2013.

11. Harris RB: Direct and indirect effects of leptin on adipocyte metabolism. Biochim Biophys Acta: May 17, 2013 (Epub ahead of print).

12. Dong M and Ren J: What fans the fire: insights into mechanisms of leptin in metabolic syndrome-associated heart diseases. Curr Pharm Des: May 14, 2013 (Epub ahead of print).

13. Simonds SE, Cowley MA and Enriori PJ: Leptin increasing sympathetic nerve outflow in obesity: A cure for obesity or a potential contributor to metabolic syndrome? Adipocyte 1: 177-181, 2012.

14. Bouchard C, Tchernof A and Tremblay A: Predictors of body composition and body energy changes in response to chronic overfeeding. Int J Obes (Lond): May 20, 2013 (Epub ahead of print)

15. Ide S, Tokuyama R, Davaadorj P, Shimozuma M, Kumasaka S Tatehara $S$ and Satomura K: Leptin and vascular endothelial growth factor regulate angiogenesis in tooth germs. Histochem Cell Biol 135: 281-292, 2011.

16. Singireddy AV, Inglis MA, Zuure WA, Kim JS and Anderson GM: Neither signal transducer and activator of transcription 3 (STAT3) or STAT5 signaling pathways are required for leptin's effects on fertility in mice. Endocrinology 154: 2434-2445, 2013.

17. Singh UP, Singh NP, Guan H, et al: Leptin antagonist ameliorates chronic colitis in IL-10 -/- mice. Immunobiology: May 13, 2013 (Epub ahead of print).

18. Alokail MS, Al-Daghri N, Abdulkareem A,Draz HM, Yakout SM, Alnaami AM, Sabico S, Alenad AM and Chrousos GP: Metabolic syndrome biomarkers and early breast cancer in Saudi women evidence for the presence of a systemic stress response and/or a pre-existing metabolic syndrome-related neoplasia risk? BMC Cancer 13: 54, 2013

19. Fiorio E, Mercanti A, Terrasi M, et al: Leptin/HER2 crosstalk in breast cancer: in vitro study and preliminary in vivo analysis. BMC Cancer 8: 305, 2008

20. Bouret SG, Bates SH, Chen S, Myers MG Jr. and Simerly RB: Distinct roles for specific leptin receptor signals in the development of hypothalamic feeding circuits. J Neurosci 32: 1244-1252, 2012.

21. Elias CF and Purohit D: Leptin signaling and circuits in puberty and fertility. Cell Mol Life Sci 70: 841-862, 2013.

22. Liu Z, Uesaka T, Watanabe H and Kato N: High fat diet enhances colonic cell proliferation and carcinogenesis in rats by elevating serum leptin. Int J Oncol 19: 1009-1014, 2001.

23. Hardwick JC, Van Den Brink GR, Offerhaus GJ, Van Deventer SJ and Peppelenbosch MP: Leptin is a growth factor for colonic epithelial cells. Gastroenterology 121: 79-90, 2001.
24. Rouet-Benzineb P, Aparicio T, Guilmeau S, Pouzet C, Descatoire V, Buyse M and Bado A: Leptin counteracts sodium butyrate-induced apoptosis in human colon cancer HT-29 cells via NF-kappaB signaling. J Biol Chem 279: 16495-16502, 2004.

25. Somasundar P, Frankenberry KA, Skinner H, et al: Prostate cancer cell proliferation is influenced by leptin. J Surg Res 118: 71-82, 2004.

26. Yu W, Gu JC, Liu JZ, et al: Regulation of estrogen receptors alpha and beta in human breast carcinoma by exogenous leptin in nude mouse xenograft model. Chin Med J (Engl) 123: 337-343, 2010.

27. Savry A, Carre M, Berges R, Rovini A, Pobel I, Chacon C, Braguer D and Bourgarel-Rey V: Bcl-2-enhanced efficacy of microtubule-targeting chemotherapy through Bim overexpression: implications for cancer treatment. Neoplasia 15: 49-60, 2013

28. Sinicrope FA and Dannenberg AJ: Obesity and breast cancer prognosis: weight of the evidence. J Clin Oncol 29: 4-7, 2011.

29. van den Brandt PA, Spiegelman D, Yaun SS, et al: Pooled analysis of prospective cohort studies on height, weight, and breast cancer risk. Am J Epidemiol 152: 514-527, 2000.

30. Key TJ, Appleby PN, Reeves GK, et al: Body mass index, serum sex hormones, and breast cancer risk in postmenopausal women. J Natl Cancer Inst 95: 1218-1226, 2003.

31. Hu X, Juneja SC, Maihle NJ and Cleary MP: Leptin - a growth factor in normal and malignant breast cells and for normal mammary gland development. J Natl Cancer Inst 94: 1704-1711, 2002.

32. Dieudonne MN, Machinal-Quelin F, Serazin-Leroy V, Leneveu MC, Pecquery R and Giudicelli Y: Leptin mediates a proliferative response in human MCF7 breast cancer cells. Biochem Biophys Res Commun 293: 622-628, 2002.

33. Rene Gonzalez R, Watters A, Xu Y, Singh UP, Mann DR, Rueda BR and Penichet ML: Leptin-signaling inhibition results in efficient anti-tumor activity in estrogen receptor positive or negative breast cancer. Breast Cancer Res 11: R36, 2009.

34. D'Esposito V, Passaretti F, Hammarstedt A, et al: Adipocyte-released insulin-like growth factor-1 is regulated by glucose and fatty acids and controls breast cancer cell growth in vitro. Diabetologia 55: 2811-2822, 2012.

35. Grisouard J, Dembinski K, Mayer D, Keller U, Muller B and Christ-Crain M: Targeting AMP-activated protein kinase in adipocytes to modulate obesity-related adipokine production associated with insulin resistance and breast cancer cell proliferation. Diabetol Metab Syndr 3: 16, 2011.

36. Kim EJ, Choi MR, Park H, et al: Dietary fat increases solid tumor growth and metastasis of 4T1 murine mammary carcinoma cells and mortality in obesity-resistant BALB/c mice. Breast Cancer Res 13: R78, 2011

37. Barone I, Catalano S, Gelsomino L, et al: Leptin mediates tumor-stromal interactions that promote the invasive growth of breast cancer cells. Cancer Res 72: 1416-1427, 2012.

38. Jung DW, Che ZM, Kim J, Kim K, Kim KY, Williams D and Kim J: Tumor-stromal crosstalk in invasion of oral squamous cell carcinoma: a pivotal role of CCL7. Int J Cancer 127: 332-344, 2010.

39. Kumar S, Kishimoto H, Chua HL, et al.: Interleukin-1 alpha promotes tumor growth and cachexia in MCF-7 xenograft model of breast cancer. Am J Pathol 163: 2531-2541, 2003.

40. Li L, Dragulev B, Zigrino P, Mauch C and Fox JW: The invasive potential of human melanoma cell lines correlates with their ability to alter fibroblast gene expression in vitro and the stromal microenvironment in vivo. Int J Cancer 125: 1796-1804, 2009.

41. Robertson SA, Leinninger GM and Myers MG Jr: Molecular and neural mediators of leptin action. Physiol Behav 94: 637-642, 2008.

42. Frankenberry KA, Skinner H, Somasundar P, McFadden DW and Vona-Davis LC: Leptin receptor expression and cell signaling in breast cancer. Int J Oncol 28: 985-993, 2006

43. Chen H, Zhang ZW, Guo Y, Wang Y, Liu Y, Luo N and Zhu Y: The proliferative role of insulin and the mechanism underlying this action in human breast cancer cell line MCF-7. J BUON 17: 658-662, 2012 